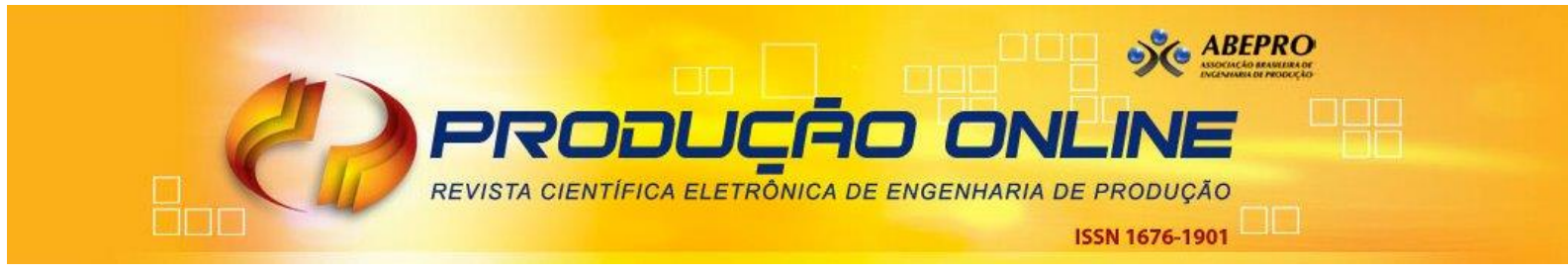

\title{
ANÁLISE DE VIABILIDADE ECONÔMICA PARA IMPLANTAÇÃO DE SISTEMA FOTOVOLTAICO RESIDENCIAL NA REGIÃO DE VILA VELHA - ES
}

\author{
ANALYSIS OF ECONOMICAL FEASIBILITY FOR IMPLEMENTATION OF \\ RESIDENTIAL PHOTOVOLTAIC SYSTEMS IN VILA VELHA REGION - ES
}

\author{
Giovanni Moreira Corteleti E-mail: firenetservice@gmail.com \\ Alexandre Coelho Santos* E-mail: alexandrecsantos@yahoo.com.br \\ *Universidade Estácio de Sá, Vila Velha, ES
}

Resumo: O constante aumento na tarifa de distribuição de energia elétrica e adoção de bandeiras tarifarias, decorrente da elevação do consumo e a estagnação da capacidade dos reservatórios hidroelétricos, demandando constante acionamento de usinas de fonte alternativas, o que tem gerado um questionamento sobre seus impactos na sociedade e no meio ambiente. Em paralelo, observamos a difusão dos sistemas fotovoltaicos, devido a redução do custo de equipamentos, instalação e um forte apelo ambiental aliado a este tipo de geração limpa. A aplicabilidade do sistema fotovoltaico apresenta viabilidade econômica em todos os casos a longo prazo, porém, não é uma solução absoluta para todos os cenários em relação a energia fornecida pela concessionária distribuidora local em curto prazo. O objetivo deste artigo é analisar a viabilidade econômica da implantação de um sistema fotovoltaico em residências na cidade de Vila Velha - ES, para atingir o objetivo proposto, foi utilizado os cálculos de valor presente líquido (VPL), utilizando como base o melhor cenário momentâneo possível para distribuição por parte da concessionária e a atual situação econômica brasileira, aplicando a Selic atual como taxa de retorno. Os resultados indicam que é viável investir em energia fotovoltaica em residências na região de estudo.

Palavras-chave: Viabilidade Econômica. Sistema Fotovoltaico. Energia Elétrica. Vila Velha.

\begin{abstract}
The constant increase in the electric energy distribution tariff and the adoption of tariff flags, due to the increase in consumption and the stagnation of the capacity of the hydroelectric reservoirs, demanding constant activation of alternative power plants, which has generated a question about its impacts on society and the environment. In parallel, we observe the diffusion of photovoltaic systems, due to the reduction of equipment costs, installation and a strong environmental appeal allied to this type of clean generation. The applicability of the photovoltaic system is economically feasible in all cases in the long run, however, it is not an absolute solution for all scenarios in relation to the energy supplied by the local distribution concessionaire in the short term. The objective of this article is to analyze the economic viability of the implantation of a photovoltaic system in residences in the city of Vila Velha - ES, to reach the proposed objective, using calculations of net present value (NPV), using as basis the best momentary scenario possible for distribution by the concessionaire and the current Brazilian economic situation, applying the current Selic rate of return. The results indicate that it is feasible to invest in photovoltaic energy in residences in the region of study.
\end{abstract}

Keywords: Economic viability. Photovoltaic System. Electricity. Vila Velha.

\section{INTRODUÇÃO}

A geração de energia elétrica através do sol se dá pelo efeito fotovoltaico, 
fenômeno que ocorre quando a luz, ou a radiação eletromagnética do sol, incide sobre uma célula composta de materiais semicondutores com propriedades específicas (VILLALVA, 2015). Através do Sistema de Compensação de Energia, a unidade com um sistema fotovoltaico gera a energia durante o dia, consumindo parte ou toda essa energia gerada, sendo que se houver excedente, essa energia é enviada para a concessionária e poderá ser utilizada novamente pela unidade em até 60 meses (ANEEL, 2017).

A demanda crescente pelo consumo de energia elétrica é observável a nível mundial, principalmente no setor industrial, culminando no aumento da concentração de Gases do Efeito Estufa (GEE), em especial o dióxido de carbono (CO2), na atmosfera, intensificando o efeito estufa. Logo, é visto como um grande desafio as consequências ambientais decorrentes da produção e 0 uso dos recursos energéticos. A produção, distribuição, transformação e consumo de energia devem ser orientados de modo a garantir o desenvolvimento, sem ampliar os efeitos negativos à sociedade e ao meio ambiente (CAMIOTO, 2014).

Segundo Câmara (2011), uma alternativa para enfrentar o caráter danoso e limitado das atuais fontes de energia é a utilização de tecnologias limpas e renováveis de geração, estas fontes naturais são capazes de se regenerar e, portanto, virtualmente inesgotáveis, além de decisivas no combate ao efeito estufa, em contrapartida aos recursos não renováveis. (ECOTURISMO, 2009).

Segundo o relatório "Renewable Energy and Jobs" da International Renewable Energy Agency (IRENA) estima-se que as energias renováveis empregaram cerca de 7,7 milhões de pessoas, direta ou indiretamente, em torno do mundo em 2014, não considerando as grandes hidrelétricas (IRENA, 2015). Além da estimativa de que a geração de energia solar já reduz as emissões globais de $\mathrm{CO} 2$ em números entre 200-300 milhões de toneladas por ano (IRENA, 2016).

O presidente da Empresa de Pesquisa Energética (EPE), Maurício Tolmasquim, afirma que a geração de energia fotovoltaica é mais econômica em 98\% do mercado nacional e a ANEL estima que o Brasil terá, até 2024, 500 mil unidades geradoras de energia fotovoltaica gerando em torno de 2 giga watts(GW), superando assim a geração da usina nuclear de Angra 2 (ANEEL, 2015).

Alguns dos incentivos legais já estimulam o uso da energia fotovoltaica, como 
é o caso da resolução normativa ํo 482, de 17 de abril de 2012, que permite a venda do excedente da produção para a concessionária de energia elétrica local (ANEEL, 2012).

Mesmo com um custo consideravelmente elevado em relação a outras tecnologias de geração de energia, o sistema fotovoltaico, já é bem difundido de acordo com os dados divulgados pela Associação Brasileira de Energia Solar Fotovoltaica (ABSOLAR) o país havia atingido em 2013, 1 giga watt (GW) gerados mensalmente em projetos operacionais da fonte solar fotovoltaica conectados na matriz elétrica, potência é suficiente para abastecer 500 mil residências do país, produzindo energia renovável, limpa, sustentável e competitiva capaz de suprir o consumo de dois milhões de brasileiros.

Este artigo tem como objetivo apresentar o desenvolvimento do processo de análise de viabilidade econômica para a implantação de um sistema fotovoltaico em residência urbana para 4 moradores, localizada na região de Vila Velha, Espirito Santo, bem como todos os fatores técnicos e legais que interferem na viabilidade de adoção deste sistema de geração de energia, levando-se em consideração que o custo $\mathrm{x}$ benefício da geração fotovoltaico em uma residência variam muito de acordo com a região, foi adotada uma região específica para melhor precisão e controle das variantes a serem levadas em consideração, como, taxas fiscais, dados estatísticos de consumo, incidência de radiação solar e outros dados inerentes ao investimento e sua avaliação de viabilidade.

\section{REFERENCIAL TEÓRICO}

\subsection{Dados de processos e geração}

Microgeradores e minigeradores solares fotovoltaicos (FV) são sistemas de geração elétrica de pequena e média potência, normalmente instalados para produzir energia suficiente para alimentar uma casa, um edifício ou, até mesmo, um galpão de uma indústria (SCHEIDT, 2013).

Na Figura 01, podemos observar que o parque solar de Bom Jesus da Lapa o Complexo Lapa começou a gerar energia em maio de 2017 e já opera com sua capacidade total. A usina é capaz de gerar cerca de $340 \mathrm{GWh}$ por ano, o suficiente 
para atender às necessidades anuais de consumo de energia de mais de 166 mil lares brasileiros, evitando a emissão de cerca de 198 mil toneladas de CO2 na atmosfera.

Figura 01 - Parque solar de Bom Jesus da Lapa

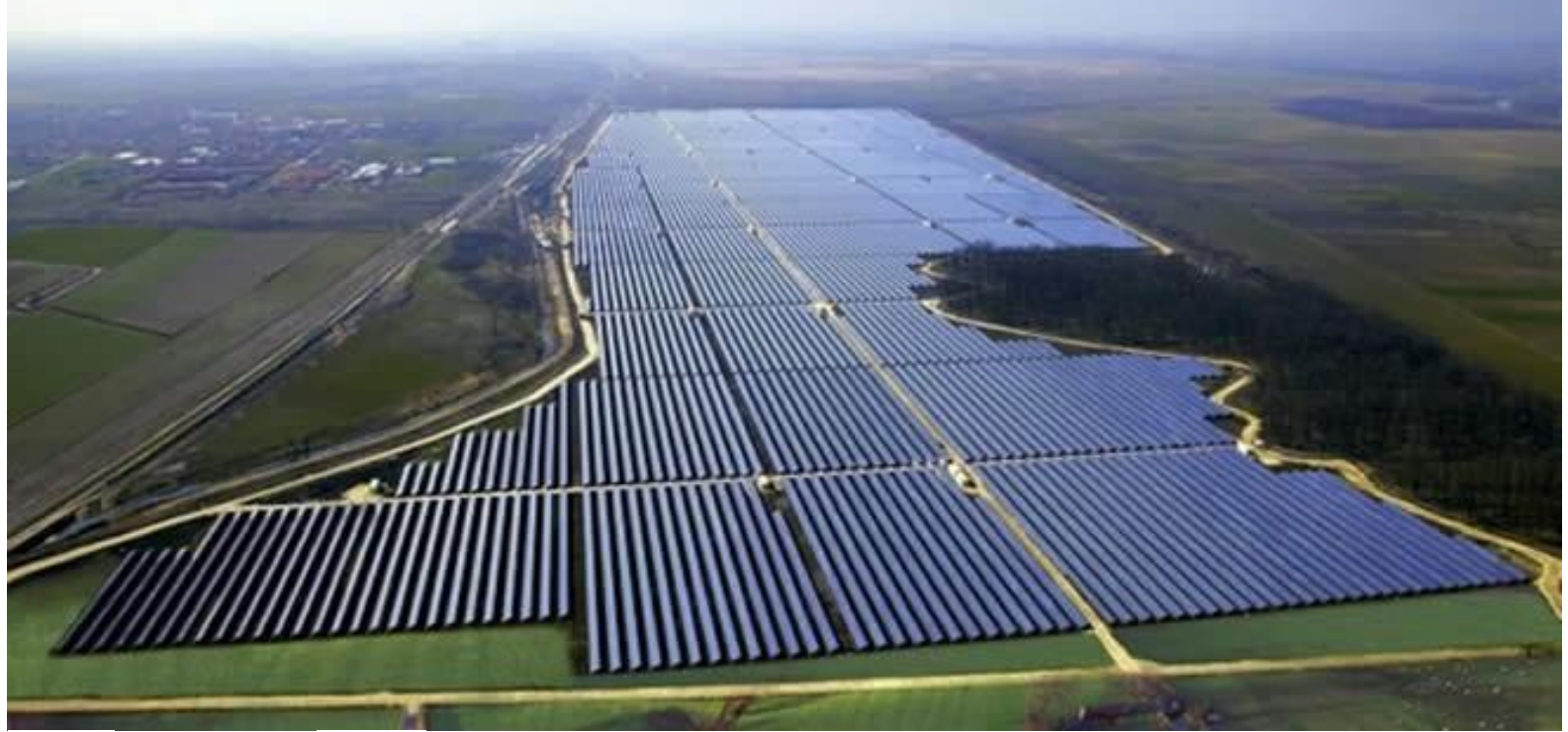

Fonte: Portal Lubes (2017).

Diferente dos parques solares que geram grandes quantidades de energia, os microgeradores são sistemas com potência de até $75 \mathrm{~kW}$, e minigeradores, acima de 75 kW e até 5 MW, segundo a Resolução Normativa REN 482/2012 da ANEEL, alterada pela REN 687-2015.

O Atlas Brasileiro de Energia Solar é um documento que faz parte do projeto SWERA (Solar and Wind Energy Resource Assessment), que visa criar um banco de dados para desenvolvimentos e pesquisas relacionadas à área de geração de energia elétrica solar ou eólica (PEREIRA et al., 2006).

Seus mapas abrangem todo o território brasileiro, possui dados como; Modelo de transferência radiativa; Modelos físicos para obtenção de estimativas de irradiação; Modelo Brasil-SR; Base de dados; Dados de satélite; Dados climatológicos; Temperatura e visibilidade; Albedo de superfície; Umidade relativa; Altitude; Dados de irradiação solar; Rede SONDA; Rede de plataformas de coleta de dados (PCD); Níveis de confiabilidade das estimativas de irradiação solar; Inter comparação de modelos; Comparação com dados coletados em superfície; Validação da irradiação global; Validação da DNI; Mapas solarimétricos; Mapas de 
radiação solar global horizontal; Média anual; Média sazonal; Mapas de radiação solar PAR; Média anual; Média sazonal; demonstrando de forma técnica todo potencial solar brasileiro.

Na Figura 02, é apresentado o mapa brasileiro e seus índices de irradiação.

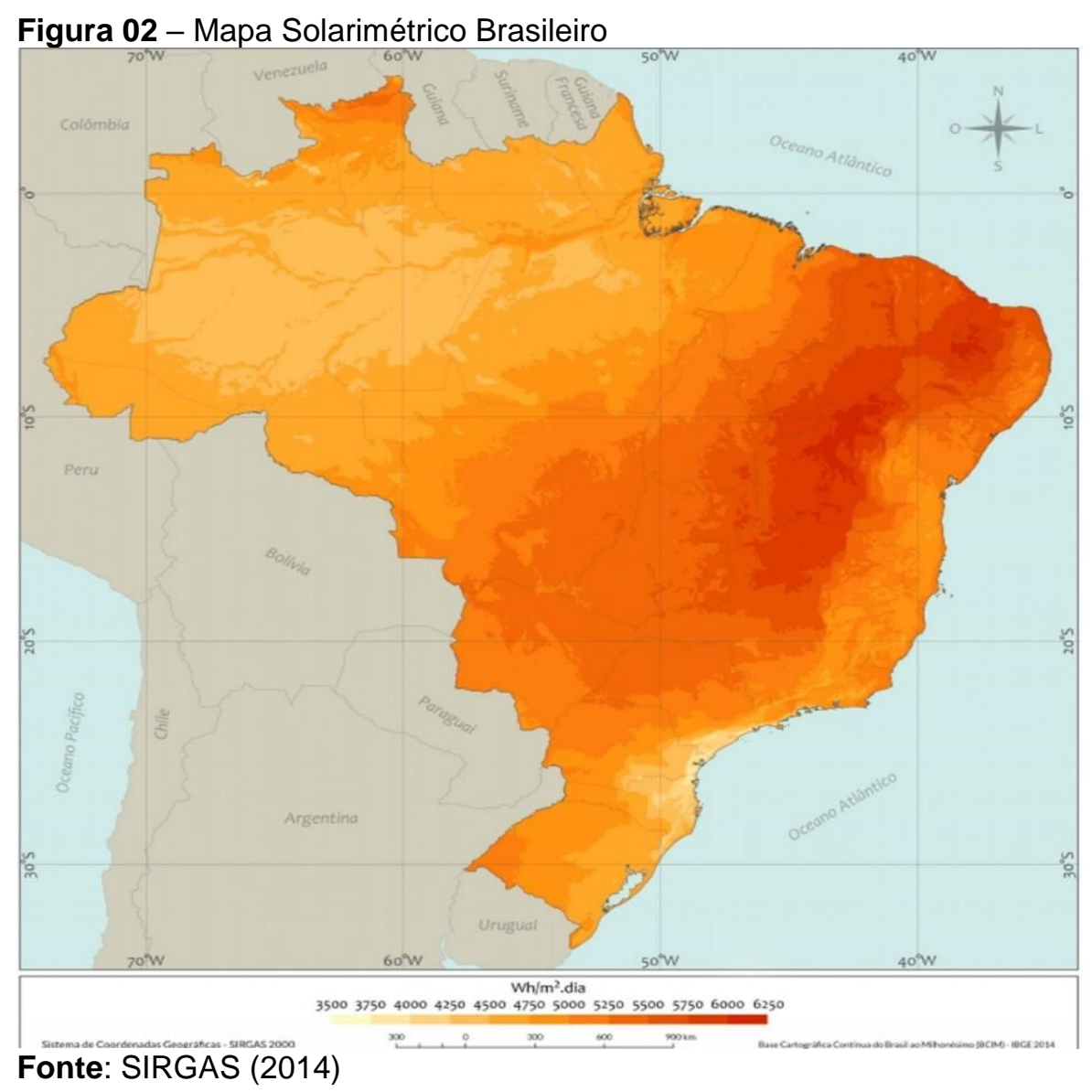

O Brasil possui uma das maiores fontes de silício do mundo, material esse que é uma das principais matérias primas utilizadas na fabricação das placas fotovoltaicas, além de possuir uma irradiação solar excelente em praticamente toda extensão territorial, permitindo altos níveis de eficiência.

Apesar do enorme potencial, nem sempre o seu uso é economicamente viável em comparação com outras fontes energéticas, devido às limitações tecnológicas na eficiência dos painéis e principalmente baterias, no caso dos sistemas off-grid. Existem também dificuldades como incentivos governamentais insuficientes e escassez de informações sobre os custos e os retornos financeiros. 


\subsection{Tecnologia aplicada na produção dos painéis fotovoltaicos}

Os painéis fotovoltaicos são vistos como a peça chave do sistema, conhecidos também como módulos fotovoltaicos, são compostos por células, que são quem propriamente realizam a conversão e a tecnologia das suas respectivas células é o que os identificam.

A tecnologia tradicional consiste na utilização do silício cristalino (c-Si) em sua constituição, essa tecnologia hoje é responsável por cerca de $80 \%$ da produção de módulos a nível mundial devido sua robustez e confiabilidade. Atualmente existem duas tecnologias aplicadas ao silício cristalino.

\subsection{Silício Monocristalino (m-Si)}

A primeira delas é o silício monocristalino ( $\mathrm{m}-\mathrm{Si})$, que consiste no tratamento do silício cristalino com uma quantidade extremamente pura do elemento, tendo eficiência iniciada em 12\% e podem chegar a 16\% (ZYTECH, 2012). Existe uma tecnologia de $\mathrm{m}$-Si que move os contatos da parte superior das células para uma parte de trás, diminuindo a área de conversão perdida e consequentemente aumentando sua eficiência, embora o custo para essa mudança seja maior. Com isso módulos m-Si "back contact", como são conhecidos, podem atingir eficiências de até 20,4\% (SUNPOWER, 2011).

\subsubsection{Silício Policristalino ( $p$-Si)}

A segunda tecnologia consiste em um processo menos dispendioso e mais rápido, produzindo o silício policristalino ( $\mathrm{p}-\mathrm{Si})$, que apesar de menos eficiente na produção possui melhor custo-benefício quando comparado em custo de produção. Esse tipo de material é responsável por mais da metade dos módulos fotovoltaicos produzidos no mundo (RUTHER, 2004).

A tecnologia tradicional já foi estabelecida comercialmente, necessitando apenas de aperfeiçoados dos métodos de produção em grande escala e barateamento desta produção. 
Já o que pode ser considerada a próxima etapa da evolução tecnológica na geração fotovoltaica é conhecida pelo termo Thin Film ou tecnologia de filme fino, que em 2015 já representava aproximadamente $20 \%$ do mercado mundial de painéis solares, pois utilizam menos materiais e podem ser construídos em superfícies curvas, o que se mostra essencial em sistemas fotovoltaicos que necessitem de adaptação a superfícies, seja por característica da instalação ou estética do projeto.

As células Fotovoltaicas de película fina (TFPV) ou Painel Solar de Película Fina - Thin Film - TFSC, deposita uma ou várias camadas finas de material fotovoltaico sobre um mesmo substrato e possuem eficiência entre 7 e 16\% sendo similares a eficiência dos painéis Policristalino.

Os diferentes tipos painéis solares de filme fino podem ser categorizados pelo material fotovoltaico que é depositado sobre o substrato, hoje possuímos no mercado 4 tipos de tecnologia empregadas nos painéis solares de película fina, os que utilizam Silício amorfo (a-Si), os quem utilizam Telureto de cádmio (CdTe), os que utilizam Cobre, índio e gálio seleneto (CIS / CIGS) e a mais recente das tecnologias, as células solares fotovoltaicas orgânicas (OPV).

$\mathrm{Na}$ Figura 03, podemos observar painéis flexíveis fabricados com células solares fotovoltaicas orgânicas (OPV), fabricados pela startup mineira SUNEW. 
Figura 03 - Filme OPV passando por analise de qualidade

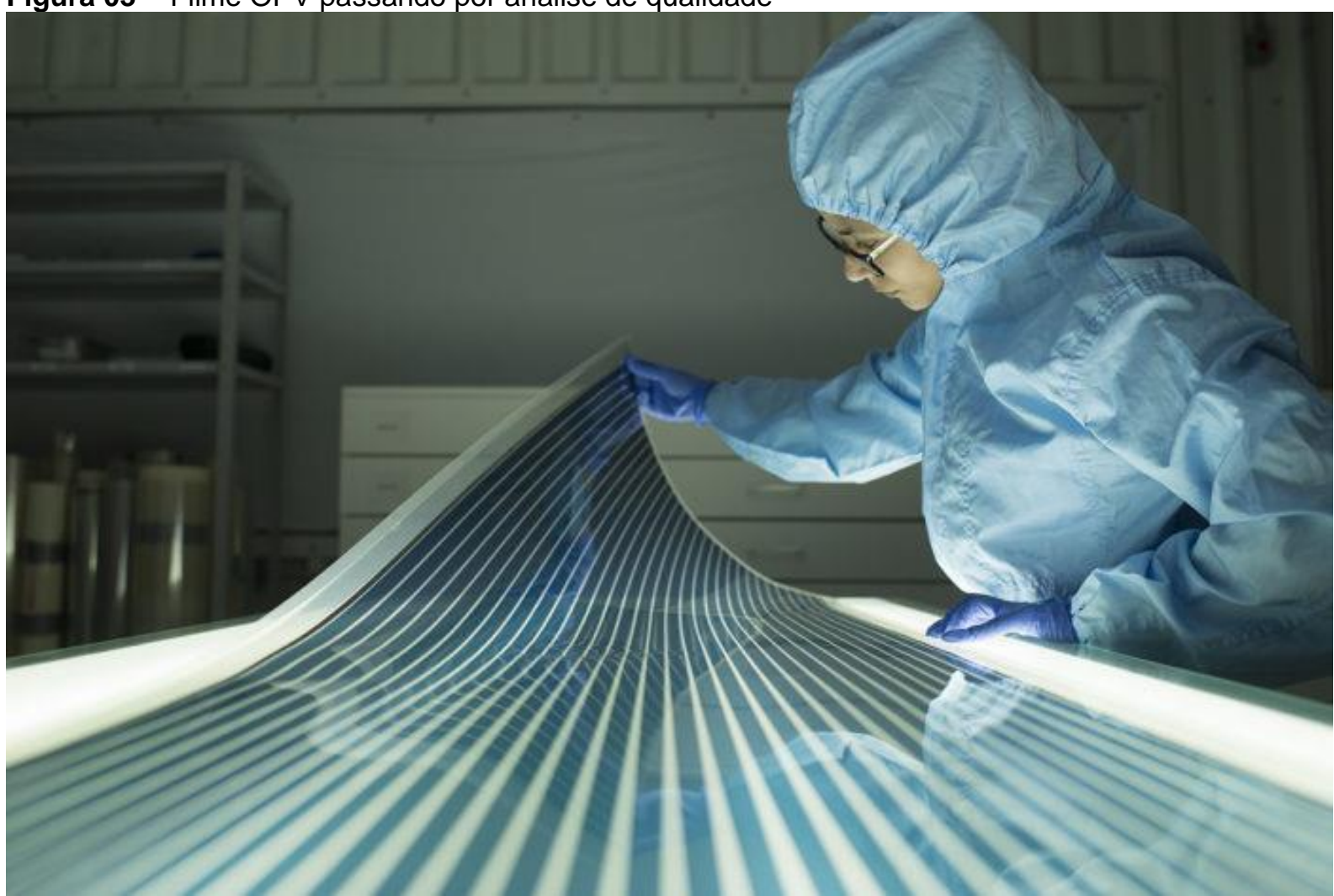

Fonte: SUNEW (2019).

\subsection{Tipos de Sistemas Fotovoltaicos}

Com base na norma técnica brasileira ABNT NBR 11704:2008 os sistemas fotovoltaicos são classificados em relação a sua interligação no sistema público de fornecimento de energia elétrica em dois tipos; Os sistemas isolados, conhecido no meio técnico sob o termo off grid, que são aqueles que não possuem qualquer tipo de conexão com o sistema público de fornecimento de energia elétrica, e tem por característica a utilização de baterias.

Os sistemas conectados à rede, conhecidos tecnicamente como sistemas on grid ou grid tie, por sua vez, são aqueles efetivamente conectados ao sistema público de fornecimento de energia elétrica, utilizando a rede elétrica como back-up da energia sobressalente ou como complemento em caso de geração insuficiente.

Estes sistemas são mais comuns por terem menor custo efetivo de implementação e normalmente não utilizam baterias para a back-up da energia gerada por terem a rede elétrica como suporte. 
Os sistemas fotovoltaicos também são classificados quanto a sua configuração pela ABNT NBR 11704:2008 e estão divididos em dois grupos; os sistemas puros, que são definidos por utilizarem apenas o sistema fotovoltaico como fonte geradora de energia elétrica. E os sistemas híbridos, que mesclam 2 ou mais fontes geradoras de energia elétrica.

Os principais valores envolvidos no levantamento do custo para a implementação de um sistema fotovoltaico são os preços dos inversores, dos painéis fotovoltaicos e da instalação de todos os equipamentos (EPE, 2012).

Devido ao alto custo de montagem e manutenção atuais dos sistemas Off Grid, decorrente do uso de baterias como forma de armazenamento, foi optante na concepção deste artigo adotar apenas como padrão para pesquisa os sistemas On Grid (ou Grid-Tie), tendo em vista que o objetivo da mesma, é comprovar, ou não, a viabilidade financeira da instalação dos sistemas fotovoltaicos.

Foi instituída pela Agência Nacional de Energia Elétrica (ANEEL), em 2012 a Resolução Normativa n 482 com o objetivo de "estabelecer as condições gerais para o acesso de microgeração e mineração distribuída aos sistemas de distribuição de energia elétrica e o sistema de compensação de energia".

A geração distribuída (GD) pode ser uma boa alternativa às formas tradicionais de produção de energia elétrica e pode ser definida como uma fonte de energia elétrica conectada diretamente à rede de distribuição ou situada no próprio consumidor. No Brasil, a definição de GD é feita a partir do Artigo $14^{\circ}$ do Decreto Lei no 5.163/2004, atualizada pelo decreto 786/2017 para as diversas aplicações, podendo oferecer um custo de produção mais baixo e qualidade de energia mais elevada do que um consumidor poderia obter da rede convencionais (Santos, 2016).

Essa resolução autoriza o Sistema de Compensação de Energia, que permite ao consumidor instalar geradores fotovoltaicos conectados à rede. Dessa forma, o consumidor pode instalar pequenos geradores em sua unidade consumidora e trocar energia com a distribuidora local, o que já é economicamente viável para alguns consumidores.

Este mercado potencial pode crescer bastante se forem concedidos incentivos como o financiamento à compra dos painéis e conversores fotovoltaicos, a isenção fiscal para a produção desses equipamentos no país e a redução do Imposto de Renda para os consumidores (EPE, 2012). 
Porém, de acordo com o IPEA (2010), as ações em termos de políticas públicas nesse sentido ainda são diminutas, não alterando o cenário, significativamente. No entanto, vale ressaltar que a energia solar deve ser impulsionada com a implementação dos conceitos de smart grid, por meio do desenvolvimento de sistemas de geração e estocagem mais eficientes, melhorando a viabilidade da geração distribuída conectada à rede.

Entretanto, deve ser enfatizado que a política governamental é a base principal, que vai apoiar o desenvolvimento do programa, com definição de orientações. Estas políticas devem estabelecer harmonia e alinhamento entre regulação, infraestrutura e mercado (FREIRE et al., 2011).

Nesse contexto, Goldemberg e Moreira, (2005) salientam que a presença do Governo é essencial para: 1) atender a demanda da sociedade por mais e melhores serviços de energia; 2 ) estimular a participação de fontes energéticas sustentáveis e duradouras; 3) priorizar o uso eficiente da energia para liberar capital aos setores mais produtivos da economia e preservar o meio ambiente; 4) utilizar o investimento em energia como fonte de geração de empregos e de estímulo à indústria nacional; 5) incorporar à matriz energética insumos importados quando isso resultar em vantagens comerciais e sociais ao país, inclusive através da abertura de exportação de produtos e serviços e, 6) produzir energia de diversas fontes, reduzindo o risco da eventual escassez de algumas delas de forma compatível com as reservas disponíveis no país.

\subsubsection{Medidor Bidirecional (Sistema On Grid)}

Para a instalação de um sistema fotovoltaico conectados à rede, os já conhecidos On Grid são necessários solicitar à concessionária a troca do medidor convencional para um modelo com leitura bidirecional, o qual registra a energia recebida da distribuidora e a energia solar que é injetada na rede elétrica (Figura 1), de forma a garantir a compensação de créditos de energia na conta de luz. Assim, para dimensionamento do medidor, deve ser levado em conta aspectos como correntes máxima e nominal, tensão nominal, potência, número de fases, entre outros (ALVES, 2016). 


\subsection{Calculo de Viabilidade Econômica}

Como citado anteriormente, os cálculos de viabilidade econômica para a implantação do sistema foram definidos segundo uso da formula matemáticofinanceira VPL, tendo como taxa de juros base a taxa Selic de abril de 2019.

A Expressão 1 define o VPL:

$$
V_{P L}=\sum_{n=1}^{n=N} \frac{F c_{t}}{(1+i)^{n}}
$$

Sendo que Fc é o fluxo de caixa; i é taxa de juros; e o símbolo $\Sigma$, somatório, indica que deve ser realizada a soma da data 1 até a data "n" dos fluxos de caixa descontados ao período inicial. Se o VPL for positivo, o projeto é economicamente viável, negativo o projeto se mostra inviável e quando o resultado retorna zero, logo, receitas e despesas são iguais, ou seja, a decisão de investir no projeto é neutra.

Como taxa de juros (i), foi necessário a definição da TMA (Taxa Mínima de Atratividade), responsável direta pela viabilidade econômica do projeto, que pode variar ao longo do tempo devido a fatores como: risco do projeto, oportunidade de investimento, estrutura tributária, capital limitado e taxas de mercado de outras corporações (BLANK, TARQUIN, 2008).

Neste trabalho, a TMA utilizada foi a Selic, pois a mesma representa a taxa básica de juros da economia brasileira e serve de referência para as outras taxas da economia. Outros trabalhos sobre viabilidade econômica do uso da fonte energética provinda do sol, como o de HIDAKA (2005), que estudou a viabilidade para racionalização energética do Instituto Criança Cidadã, também usaram como TMA a Selic em suas análises. A TMA utilizada foi de $6,50 \%$ a.a., que era o valor da taxa Selic em abril de 2019 (BANCO CENTRAL, 2019).

Com os dados definidos, deve-se montar o fluxo de caixa incremental. Nele considerou-se, assim, o investimento inicial no sistema fotovoltaico de $R \$ 27.756,00$ e um custo médio anual de $R \$ 4.423,08$, na residência objeto de estudo, em Vila Velha - ES. Este último foi calculado considerando o valor do $\mathrm{kWh}$ da energia 
elétrica, os impostos relacionados à energia elétrica e o consumo elétrico anual fornecido pela EDP.

No entanto, os impostos relacionados com a energia elétrica podem variar segundo as três bandeiras tarifárias vigentes: verde, amarela e vermelha, na bandeira verde não há acréscimo no valor da fatura, a bandeira amarela incide um acréscimo de $\mathrm{R} \$ 0,010$ por kWh consumido, mais os impostos, por fim, na bandeira vermelha, que é dividia em 2 patamares, com um acréscimo de $R \$ 0,030$ por kWh consumido no primeiro patamar e de $\mathrm{R} \$ 0,050$ por $\mathrm{KWh}$ consumido no segundo patamar, além dos impostos.

Para fins de análise foi considerado apenas os cálculos realizados na bandeira verde, por se tratar do menor custo, tendo em vista que se a instalação do sistema fotovoltaico se mostrar viável no melhor cenário, automaticamente ele terá melhor retorno em situações em que o valor cobrado é maior.

\section{CONCEPÇÃO DO ESTUDO}

Inicialmente foi realizado um estudo comparativo entre o índice de preços ao consumidor (IPCA) e a evolução do valor da tarifa de energia no período entre os anos de 1995 e 2016 no grupo B, grupamento composto de unidades consumidoras com fornecimento em tensão inferior a $2,3 \mathrm{kV}$, caracterizado pela tarifa monômia e subdividido nos seguintes subgrupos: a) subgrupo B1 - residencial; b) subgrupo B2 rural; c) subgrupo B3 - demais classes; e d) subgrupo B4 - lluminação pública (ANEEL, 2010).

Foi observado que o reajuste tarifário vem superando a inflação correspondente no mesmo período como pode ser observado na figura 04. 
Figura 04 - Evolução da Tarifa Energética x Inflação

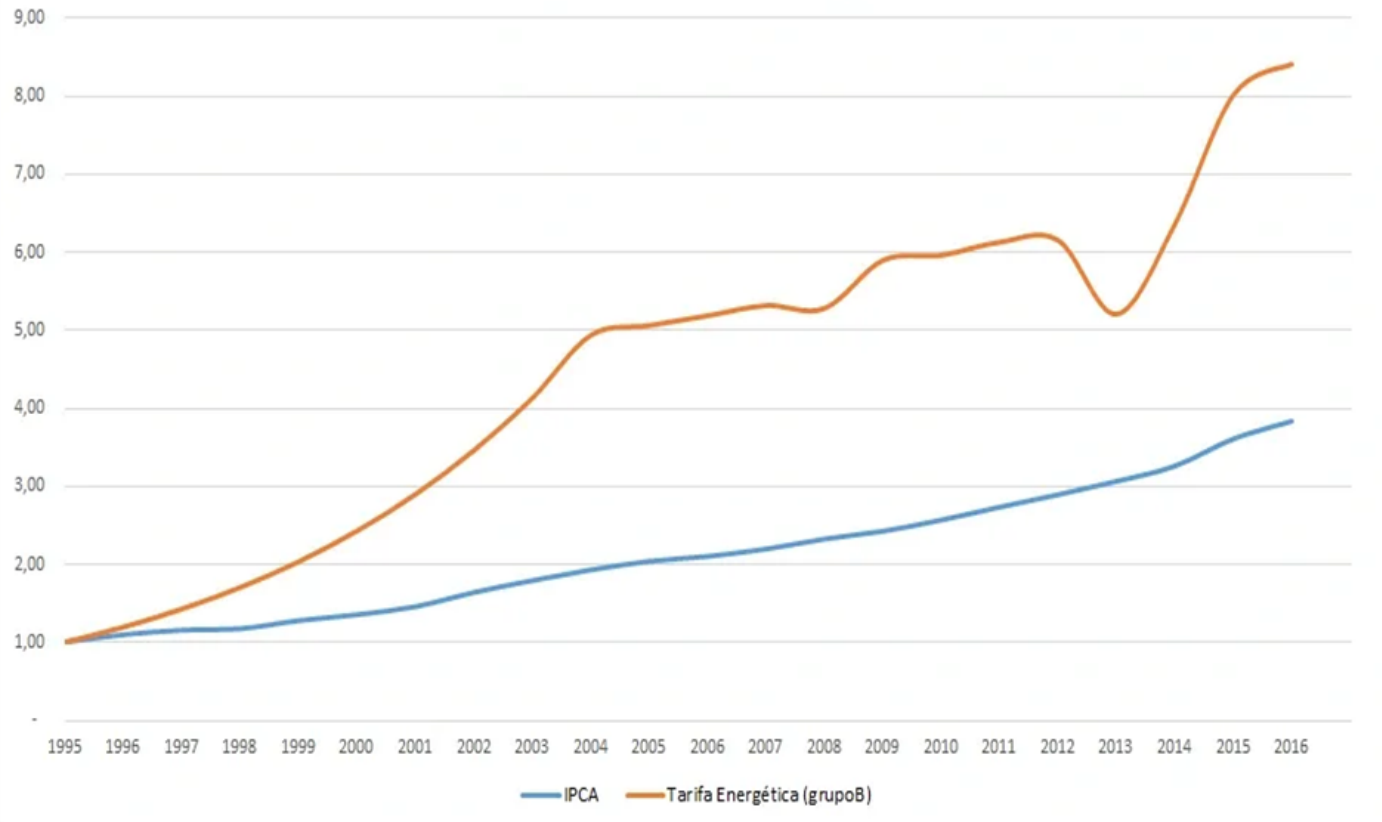

Fonte: ANEEL (2019)

Em levantamento realizado do histórico de consumo da residência de estudo no período de novembro de 2017 a março de 2019, foi observado uma média de consumo de 442KWh e uma média de valor pago a concessionária de energia de $\mathrm{R} \$ 368,59$ mensais, como pode ser observado na tabela 1 . O valor do $\mathrm{KWh}$ foi calculado em $0,89 \mathrm{R} \$$ por $\mathrm{KWh}$, acrescido de todos os encargos $(0,56 \mathrm{R} \$$ do valor do KWh, $0,56 \%$ do PIS, $2,56 \%$ do COFINS, $25 \%$ de ICMS e $31,17 \mathrm{R} \$$ de taxa de iluminação pública), usando como multiplicador a bandeira verde (sem adicional de calculo no valor).

Logo para suprirmos as necessidades de consumo de energia anual da residência seria necessária uma produção fotovoltaica de $442 \mathrm{KWh}$ médio por mês, ou 3,90KWp, levando-se em consideração um importante fator, a irradiância.

Para o dimensionamento do sistema e determinar a radiação solar disponível no local, foi utilizado o software Radiasol 2 (LABSOL, 2016). A irradiância é uma grandeza empregada para quantificar a radiação e é expressa em $\mathrm{W} / \mathrm{m}^{2}$, esta medida consiste em mostram as variações ao longo do ano, da radiação solar extraterrestre, terrestre global e difusa no plano horizontal, tornado possível mensurar a quantidade de energia a ser absorvida pela superfície em cada horário do dia e em diferentes cenários. 
Tabela 1 - Histórico de consumo de energia

\begin{tabular}{lll}
\hline Mês / Ano & KWh & R\$ \\
\hline $04 / 2019$ & 440 & $375,37 \mathrm{R} \$$ \\
$03 / 2019$ & 466 & $415,07 \mathrm{R} \$$ \\
$02 / 2019$ & 468 & $416,46 \mathrm{R} \$$ \\
$01 / 2019$ & 489 & $401,44 \mathrm{R} \$$ \\
$12 / 2018$ & 469 & $397,66 \mathrm{R} \$$ \\
$11 / 2018$ & 455 & $415,73 \mathrm{R} \$$ \\
$10 / 2018$ & 442 & $427,80 \mathrm{R} \$$ \\
$09 / 2018$ & 357 & $338,16 \mathrm{R} \$$ \\
$08 / 2018$ & 442 & $392,48 \mathrm{R} \$$ \\
$07 / 2018$ & 416 & $351,52 \mathrm{R} \$$ \\
$06 / 2018$ & 422 & $357,05 \mathrm{R} \$$ \\
$05 / 2018$ & 452 & $345,14 \mathrm{R} \$$ \\
$04 / 2018$ & 442 & $322,55 \mathrm{R} \$$ \\
$03 / 2018$ & 458 & $338,99 \mathrm{R} \$$ \\
$02 / 2018$ & 454 & $349,98 \mathrm{R} \$$ \\
$01 / 2018$ & 487 & $376,57 \mathrm{R} \$$ \\
$12 / 2017$ & 395 & $307,16 \mathrm{R} \$$ \\
$11 / 2017$ & 386 & $305,55 \mathrm{R} \$$ \\
\hline
\end{tabular}

Fonte: Dados coletados pelo autor das contas de luz da residência de estudo (2019)

A escolha do local para a instalação dos painéis fotovoltaicos pode ser determinante para o desempenho do sistema. São vários os fatores que influenciam no desempenho de geração dos painéis, dentre eles, podem-se ressaltar: o ângulo de inclinação em relação ao Norte, sombreamentos, e a capacidade de trocar calor com o meio - ventilação (CEPEL; CRESESB, 2014).

A irradiância solar histórica medida na região sudeste é de $1375 \mathrm{~W} / \mathrm{m}^{2}$ de pico e $5 \mathrm{KW} . \mathrm{h} . \mathrm{m}^{2} / \mathrm{dia}$ em condições normais de céu limpo em regiões onde temos as maiores incidências solares, medindo-se a irradiância pode-se calcular a energia recebida do sol num determinado período, mensurando assim os valores da irradiância ao longo do tempo, obtém-se o valor da energia recebida do sol durante 0 dia por unidade de área.

No Brasil, devido a sua posição privilegiada em relação ao Sol, é melhor que os painéis sejam instalados com inclinação menor que a latitude - caso não seja possível instalar no mesmo grau da latitude do local - do que com inclinações maiores que a latitude (PORTAL SOLAR, 2017). 
Figura 05 - Gráficos de irradiância dos cenários mais recorrentes entre 15/05/18 e 15/05/19

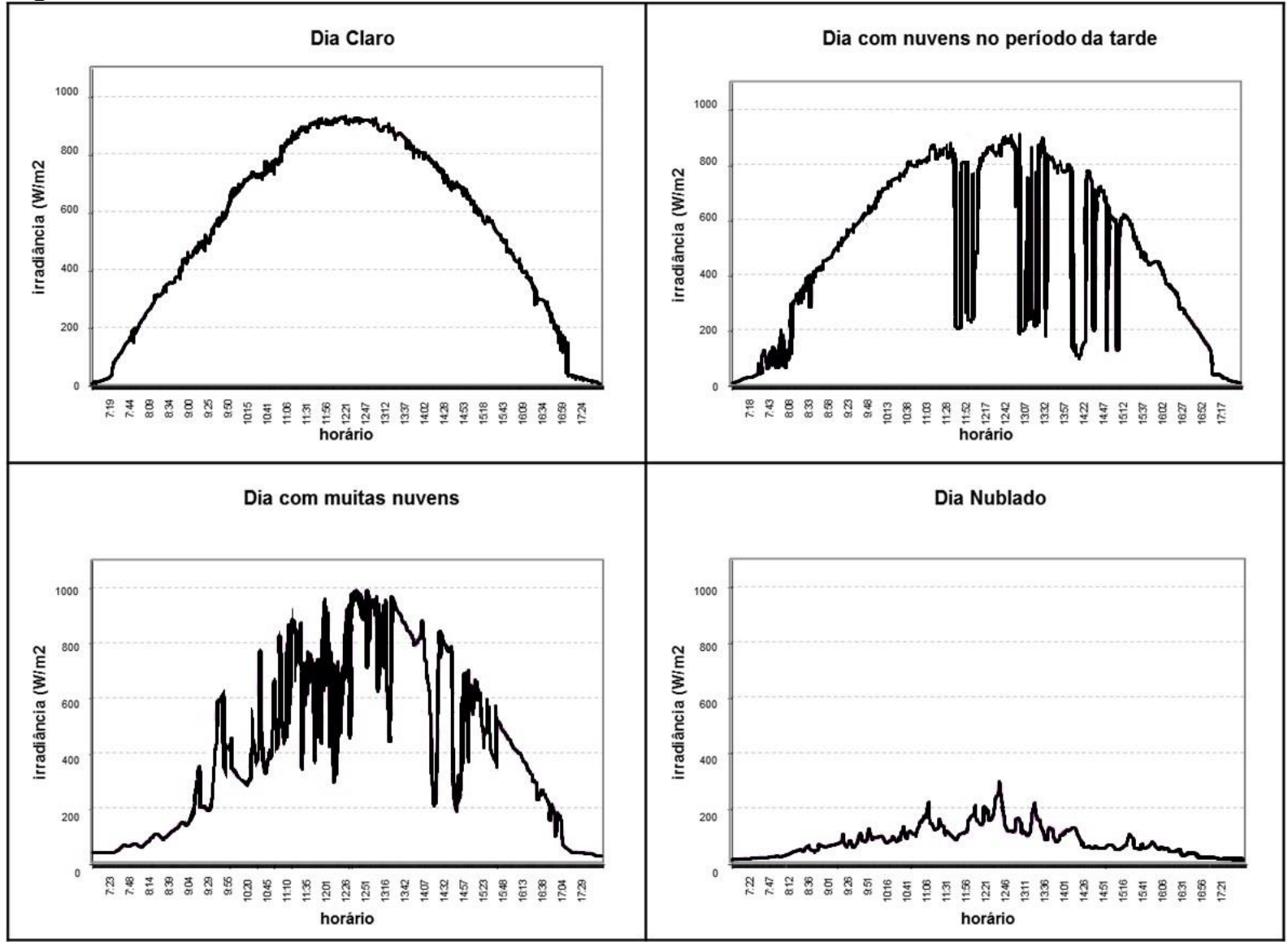

Fonte: Dados aferidos pela estação meteorológica Vitória-A612 (2019)

Para obtermos a média real de energia gerada utilizamos uma média entre o tempo de irradiância nos dois cenários extremos que que são um céu totalmente limpo e um extremamente nublado, obtendo assim a porcentagem de $31,46 \%$ de eficiência produtiva média em relação a capacidade máxima de $1375 \mathrm{~W} / \mathrm{m}^{2}$, o que determina nosso valor de potência de trabalho para a realização dos cálculos, desconsiderando os valores de pico normalmente utilizados, pois seus dados retornam resultados acima da geração média real.

Para obter o maior potencial produtivo possível, foi utilizado como base de cálculo o pico de irradiação, aproveitando assim toda disponibilidade de incidência solar, obtendo uma média produtiva de $314,6 \mathrm{~W} / \mathrm{m} 2$ diários tendo seu pico de produção as 14 horas do dia 25 de dezembro de 2018 com uma irradiação de $1164,72 \mathrm{~W} / \mathrm{m}^{2}\left(4193 \mathrm{~kJ} / \mathrm{m}^{2}\right)$ aferida pelo piranômetro da estação meteorológica Vitória-A612, como observado na figura 06, localizada no campus da UFES em Vitoria - ES. 
Figura 06 - estação meteorológica Vitória-A612

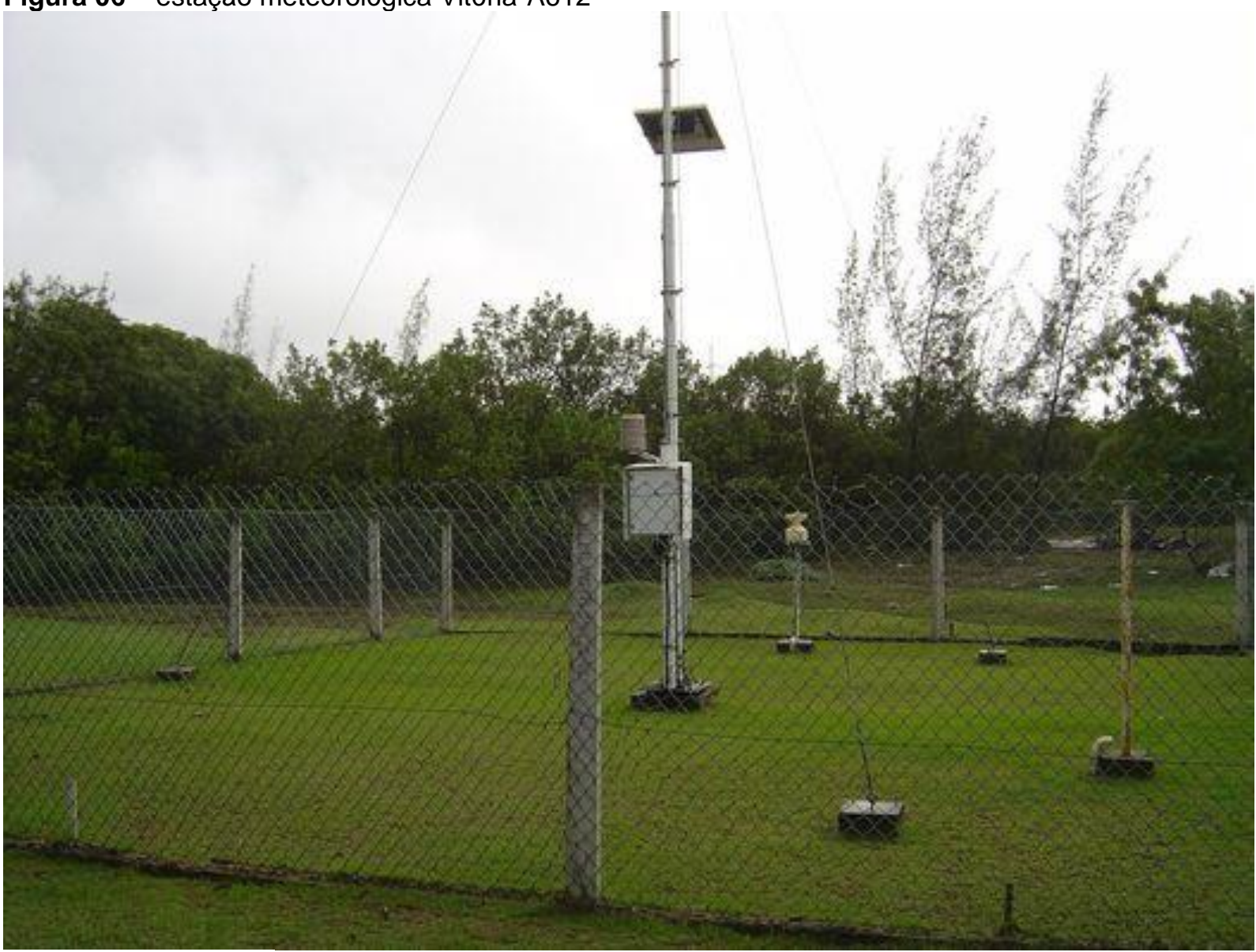

Fonte: INMET (2019).

O melhor custo $x$ benefício do mercado em pesquisa realizada no dia 15 de maio de 2019 foi o painel solar policristalino de 325W da NEXT ENERGY com um custo por painel de $R \$ 650,00$ com capacidade de geração de $167 \mathrm{Wp}$ por metro quadrado, sendo necessário assim a instalação de 12 painéis, utilizando uma área total de $31,20 \mathrm{M}^{2}$ de capitação, com capacidade de geração de $3,90 \mathrm{KWp}$ a um custo de $R \$ 7.800,00$ de painéis.

Para realizar a conversão da energia capitada pelos painéis foi selecionado o Inversor Fronius Primo 6.0-1 de 6.000W para que trabalhe com folga sobre os $3,90 \mathrm{KWp}$ produzido pelos painéis com um custo de $R \$ 12.290,00, R \$ 2.866,00$ de custo relativos aos conectores Mc4 e Mc4y, o Disjuntor Schneider 1000DC 10A para sistemas fotovoltaicos, os cabos que interligam o sistema, estrutura em aço e parafusos de fixação, porcas, materiais de consumo para a instalação como silicone, fita isolante entre outros e uma valor de $\mathrm{R} \$ 4.800,00$ referente a mão de obra da 
instalação, gerando assim um custo total para montagem do sistema de $R \$$ $27.756,00$.

Foi calculado a média de reajuste anual da tarifa de energia cobrada pela concessionária nos últimos 5 anos, como pode ser visualizado na tabela 2, para ser aplicada sobre o valor médio pago da conta para projeções futuras, obtendo-se a média de reajuste anual de 16,068\% ao ano (1,339 a.m), que somada a Selic de $6,5 \%$ ao ano (0,541a.m.) e ao valor médio da conta de energia de 368,59R\$ $(4423,08 \mathrm{R} \$$ em um ano) nos proporciona todos os dados necessários para os cálculos de viabilidade da instalação.

Tabela 2 - Histórico de reajuste tarifário 2014 - 2018

\begin{tabular}{|c|c|c|c|}
\hline ANO & $\begin{array}{l}\text { RESOLUÇÃO E } \\
\text { PUBLICAÇÃO }\end{array}$ & MOTIVO & EFEITO MÉDIO AO CONSUMIDOR \\
\hline 2018 & $\begin{array}{l}\text { Resolução } \\
\text { homologatória nำ2.432 } \\
\text { de 07/08/2018 } \\
\text { Resolução }\end{array}$ & Reajuste tarifário anual & $15,87 \%$ \\
\hline 2017 & $\begin{array}{l}\text { homologatória nํ⒉283 } \\
\text { de } 31 / 07 / 2017\end{array}$ & Reajuste tarifário anual & $9,34 \%$ \\
\hline 2016 & $\begin{array}{l}\text { Resolução } \\
\text { homologatória n².118 } \\
\text { de 02/08/2016 } \\
\text { Resolucão }\end{array}$ & $\begin{array}{l}\text { Revisão tarifária } \\
\text { periódica }\end{array}$ & $-2,80 \%$ \\
\hline \multirow[t]{2}{*}{2015} & $\begin{array}{l}\text { homologatória n¹.928 } \\
\text { de 04/08/2015 } \\
\text { Resolucão }\end{array}$ & Reajuste tarifário anual & $2,04 \%$ \\
\hline & $\begin{array}{l}\text { homologatória n¹.858 } \\
\text { de } 27 / 02 / 2015 \\
\text { Resolução }\end{array}$ & Revisão extraordinária & $26,35 \%$ \\
\hline 2014 & $\begin{array}{l}\text { homologatória } n^{\circ} 1.768 \\
\text { de } 05 / 08 / 2014\end{array}$ & Reajuste tarifário anual & $26,54 \%$ \\
\hline
\end{tabular}

Inicialmente os cálculos foram realizados de forma mensal para obtermos um ajuste mais fino nos valos a serem exibidos, porem o volume de dados gerado foi muito grande, logo foi optante converter estes dados para uma exibição anual, em paralelo todos os cálculos foram refeitos em um panorama anual para se obter um prova real, a comparação dos resultados que foi positiva com uma margem de erro inferior a $1 \%$, retornando praticamente os mesmos valores tanto em cálculos mensais como em cálculos anuais, os cálculos de VPL realizado para o projeto estão dispostos na tabela 3 abaixo. 
Tabela 3 - Calculo de VPL do projeto

\begin{tabular}{llll}
\hline & $\begin{array}{c}\text { Saldo do } \\
\text { Investimento }\end{array}$ & $\begin{array}{c}\text { Somatório anual de } \\
\text { faturas com projeção } \\
\text { de reajuste }\end{array}$ & $\begin{array}{c}\text { Somatório anual de } \\
\text { faturas com VPL } \\
\text { aplicado a Selic }\end{array}$ \\
\hline Ano 0 & $\mathrm{R} \$-27.756,00$ & $\mathrm{R} \$ 0,00$ & $\mathrm{R} \$ 0,00$ \\
Ano 1 & $\mathrm{R} \$-23.602,87$ & $\mathrm{R} \$ 4.423,08$ & $\mathrm{R} \$ 4.153,13$ \\
Ano 2 & $\mathrm{R} \$-19.076,63$ & $\mathrm{R} \$ 5.133,78$ & $\mathrm{R} \$ 4.526,24$ \\
Ano 3 & $\mathrm{R} \$-14.142,74$ & $\mathrm{R} \$ 5.958,68$ & $\mathrm{R} \$ 4.932,89$ \\
Ano 4 & $\mathrm{R} \$-8.766,68$ & $\mathrm{R} \$ 6.916,12$ & $\mathrm{R} \$ 5.376,06$ \\
Ano 5 & $\mathrm{R} \$-2.907,64$ & $\mathrm{R} \$ 8.027,40$ & $\mathrm{R} \$ 5.859,04$ \\
Ano 6 & $\mathrm{R} \$ 3.477,78$ & $\mathrm{R} \$ 9.317,24$ & $\mathrm{R} \$ 6.385,42$ \\
Ano 7 & $\mathrm{R} \$ 10.436,87$ & $\mathrm{R} \$ 10.814,33$ & $\mathrm{R} \$ 6.959,09$ \\
Ano 8 & $\mathrm{R} \$ 18.021,17$ & $\mathrm{R} \$ 12.551,98$ & $\mathrm{R} \$ 7.584,30$ \\
Ano 9 & $\mathrm{R} \$ 26.286,84$ & $\mathrm{R} \$ 14.568,83$ & $\mathrm{R} \$ 8.265,67$ \\
Ano 10 & $\mathrm{R} \$ 35,295,10$ & $\mathrm{R} \$ 16.909,75$ & $\mathrm{R} \$ 9.008,26$ \\
PayBack $=5,786$ Anos & $\mathrm{VPL}=\mathrm{R} \$ 35.295,10$ & $\mathrm{TMA}=6,500 \%$ a.a & $\mathrm{TMA}=0,54165 \%$ a.m. \\
\hline Fan
\end{tabular}

Fonte: Dados coletados pelo autor das contas de luz da residência de estudo (2019)

O VPL foi calculado tendo como base uma vida útil de 10 anos que é a média de vida útil do componente de menor durabilidade, o inversor, já que os painéis têm garantia de 25 anos dentro de uma eficiência de produção de $80 \%$ ou superior, o fluxo de caixa levou em consideração valores adequados pela media de reajustes dos últimos 5 anos na tarifa de energia da concessionária, valores estes aplicados a VPL com uma TMA igual a Selic de 6,5\%a.a.

O PayBack que é o período de recuperação do investimento retornou um valor calculado em 5,786 anos, que convertido representa 5 anos, 9 meses e 13 dias para o total retorno do valor aplicado no projeto.

\section{RESULTADOS E DISCUSSÃO}

É de conhecimento que energia é um dos componentes essenciais para o desenvolvimento social e econômico das nações (e, consequentemente, das cidades). Este desenvolvimento, por sua vez, deve estar intimamente ligado ao uso sustentável, eficiente e seguro de energia com base em abordagens ecológicas e economicamente viáveis para o futuro da sociedade a curto e longo prazo.

De acordo com a teoria de externalidade de rede, espera-se que em poucos anos os sistemas fotovoltaicos fiquem mais competitivos e atrativos devido a efeitos como o da economia de escala, estabilidade econômica do mercado nacional, redução de preços dos componentes do sistema, incentivos ficais e fabricação local de componentes, o que implica uma redução no período de PayBack previsível. 
Considerando a expectativa projetada de que o sistema se pague dentro de $60 \%$ do período de garantia dos componentes e dentro de um período de $24 \%$ do tempo total de vida útil médio especificado pelos fabricantes, com base no que foi apresentado, concluímos pela viabilidade econômica da instalação de sistemas fotovoltaicos na região de Vila Velha - ES.

Além da viabilidade econômica atestada, deve ser levado em consideração também a questão ambiental, de maneira sustentável os usuários do sistema fotovoltaico economizam financeira, e ecologicamente. Existem questionamentos sobre a sustentabilidade da geração fotovoltaica em relação ao custo energético para a fabricação de seus componentes, porem a não fabricação demanda um custo igual ou superior para outros tipos de fontes não sustentáveis.

É indicado que se utilize telhados ou estruturas elevadas, onde abaixo dos painéis exista uma utilização implicando que área utilizada para a geração também seja utilizada para outras finalidades tendo um aproveitamento ainda mais eficiente. Referente a limpeza dos painéis, que é a sua única manutenção periódica necessária, que normalmente utiliza água em seu processo, deve ser realizada de maneira consciente, tendo em vista que o desperdício de água é contrario ao objetivo de sustentabilidade.

\section{CONSIDERAÇÕES FINAIS}

Por fim, espera-se que este trabalho forneça informações úteis para que estudos semelhantes sejam desenvolvidos em outras regiões, a fim de que fontes renováveis de energia sejam cada vez mais utilizadas contribuindo para a redução de emissões e o bem-estar social. Porém, para isso é importante que as implantações desses sistemas possuam viabilidade econômica. Logo, ressalta-se que incentivos públicos são importantes para motivar e viabilizar o uso dessa fonte energética em residências.

É importante ressaltar que o presente estudo se destina a região de Vila Velha no estado do Espírito Santo e que a sua adaptação para uso em outras regiões deve ser realizada levando-se em consideração os fatores geográficos, irradiação, fatores climáticos, geolocalização, valores monetários de frete para os equipamentos e mão de obra local. 
Ressalta-se ainda que, no presente estudo, não foi analisado diretamente o impacto que a modernização da tecnologia nas distribuidoras, o uso de mais dispositivos eletrônicos devido a difusão tecnológica e os smart grids podem promover nesses valores, logo, futuros trabalhos podem ser desenvolvidos abordando e mensurando de forma mais direta a influência e impacto desses fatores no preço do KWh e no consumo de energia, bem como a influência de possíveis alterações na política energética do país.

\section{REFERÊNCIAS}

ABINEE - Associação Brasileira da Indústria Elétrica e Eletrônica. Propostas para inserção da energia solar fotovoltaica na matriz elétrica brasileira, 2012. Disponível em: http://www.abinee.org.br/informac/arquivos/profotov.pdf. Acesso em: 08 set. 2018.

AGÊNCIA NACIONAL DE ENERGIA ELÉTRICA. ANEEL aprova revisão tarifária da Light (RJ). Disponível em: http://www.aneel.gov.br/sala-de-imprensa-exibicao2//asset publisher/zXQREz8EVIZ6/content/aneel-aprova-reajuste-tarifario-da-light-ri-/ $\underline{656877 .}$

AGÊNCIA NACIONAL DE ENERGIA ELÉTRICA. Bandeiras tarifárias. Disponível em: http://www.aneel.gov.br/bandeiras-tarifarias.

AGUILAR, R. S.; OLIVEIRA, L.C.S; ARCANJO, G.L.F. Energia renovável: os ganhos e os impactos sociais, ambientais e econômicos nas indústrias brasileiras. In: ENCONTRO NACIONAL DE ENGENHARIA DE PRODUÇÃO, 32., 2012. [Anais....]. Bento Gonçalves. Rio Grande do Sul: UFRGS, 2012.

ALVEZ, G.; NASICMENTO, R. Fontes alternativas e renováveis de energia no Brasil: métodos e benefícios ambientais. Disponível em:

http://www.inicepg.univap.br/cd/INIC 2016/anais/arquivos/0859 1146 01.pdf. Acesso em: 07 fev. 2019.

ANDRADE, M. M. de. Introdução à metodologia do trabalho científico. 8. ed. São Paulo: Atlas, 2007.

ANEEL - Agência Nacional de Energia Elétrica. Resolução Normativa N482, 2014.

Disponível em: http://www.solenerg.com.br/blog/wp-

content/uploads/2012/04/ResolucaoANEEL-2012-482-Fotovoltaica-conectada-a-

redeSistema-de-compensacao-de-energia.pdf. Acesso em: 09 jan. 2019

ANEEL. Agência Nacional de Energia Elétrica. Resolução Normativa N414, 2010.

Disponível em:

http://www.aneel.gov.br/home?p $\mathrm{p}$ id $=101 \& \mathrm{p} p$ lifecycle $=0 \& \mathrm{p} p$ state=maximized\&p $\mathrm{p} \mathrm{m}$ ode=view\& 101 struts action=\%2Fasset publisher\%2Fview content\& 101 returnToFullPa geURL=http\%3A\%2F\%2Fwww.aneel.gov.br\%2Fhome\%3Fp auth\%3DtKPnkZ9v\%26p p id \%3D3\%26p p lifecycle\%3D1\%26p p state\%3Dnormal\%26p p state rcv\%3D1\& 101 ass 
etEntryld=15049535\& 101 type=content \& 101 groupld=656835\& 101 urlTitle=grupob\&inheritRedirect=true Acesso em: 04 abr. 2019

BANCO CENTRAL. Histórico das taxas de juros, 2018. Disponível em: https://www.bcb.gov.br/controleinflacao/historicotaxasjuros. Acesso em: 18 jan. 2019.

BAPTISTA, A. Análise da viabilidade econômica da utilização de aquecedores solares de água em resorts no nordeste do Brasil. 2016. 156f. Dissertação (Mestre em ciências em planejamento energético), Universidade Federal do Rio de Janeiro, Rio de Janeiro. 2016.

CALIFORNIA ENERGY COMMISSION. New Solar homes partnership calculator: CECPV Calculator. Disponível em: http://www.gosolarcalifornia.ca.gov/nshpcalculator. Acesso em: 27 ago. 2017

CÂMARA, C. Sistemas fotovoltaicos conectados à rede elétrica. 68 p. Dissertação (Mestrado) - Universidade Federal de Lavras, Lavras, 2011.

CASARO, M.; MARTINS, D. Processamento eletrônico da energia solar fotovoltaica em sistemas conectados à rede elétrica. Revista Controle \& Automação, v. 21, n. 2, p. 159 172, 2009. https://doi.org/10.1590/S0103-17592010000200005

CRESESB - Centro de Referência para Energia Solar e Eólica. Tutorial de energia solar fotovoltaica, 2014. Disponível em: http://www.cresesb.cepel.br/content.php?cid=301. Acesso em: 7 jul. 2018.

CRESESB. Atlas solatimétrico do Brasil, 2000. Disponível em: http://www.cresesb.cepel.br/publicacoes/download/Atlas Solarimetrico do Brasil 2000.pdf. Acesso em: 07 fev. 2019.

EFICIEN. Alemanha é o país com maior investimento em energia solar do mundo, 2014. Disponível em: http://www.eficien.com.br/noticias/alemanha-e-o-pais-commaiorinvestimento-em-energia-solar-do-mundo/. Acesso em: 12 jan 2018.

EPE. Empresa de Pesquisa Energética. Análise da inserção da geração solar na matriz elétrica brasileira, 2012. Disponível em: http://www.mme.gov.br. Acesso em: 15 fev. 2019.

GIAMPIETRO, U.; RACY, J. Viabilidade econômica da energia solar nas áreas rurais do nordeste brasileiro. 12p. Mackenzie, 2004. DOI:

https://doi.org/10.1016/j.enpol.2011.11.055

HATTENBERGER, M. O potencial da energia eólica e solar no Brasil. Swisscam Brasil Magazine. Ed. 66, 2011. Disponível em: www.swisscam.com.br. Acesso em: 29 nov. 2011.

HIDAKA, R. Estudo de viabilidade para racionalização energética do instituto criança cidadã. 11p. Escola Politécnica, Universidade de São Paulo, São Paulo, 2005.

IPEA. Instituto de Pesquisa Econômica e Aplicada. Sustentabilidade ambiental no Brasil: biodiversidade, economia e bem-estar humano. Brasília, Ipea, 2010.

KAUARK, Fabiana. Metodologia da pesquisa: guia prático. Itabuna: Via Litterarum, 58 2010. 
KUPFER,D; HASENCLEVER,L. Economia Industrial: fundamentos teóricos e práticas no Brasil. 2. ed. Rio de Janeiro: Elsevier, 2013. DOI: https://doi.org/10.1016/B978-85-352-6368$\underline{8.00007-4}$

LAFAY; STEPHANE, J. Análise energética de sistemas de aquecimento de água com energia solar e gás. 173 p. Dissertação (Doutorado) - Escola de Engenharia, Universidade Federal do Rio Grande do Sul, Porto Alegre, 2005.

O TEMPO. Tributos fazem valor da conta de energia variar mês a mês, 2015. Disponível em: http://www.otempo.com.br/capa/economia/tributos-fazem-valor-da-conta-deenergiavariar-m\%C3\%AAs-a-m\%C3\%AAs-1.1078723. Acesso em: 10 fev. 2019.

PALISADE. Simulação de Monte Carlo, 2014. Disponível em: http://www.palisadebr.com/risk/monte carlo simulation.asp. Acesso em: 25 jan. 2019.

PRODANOV, Cleber Cristiano; FREITAS, Ernani Cesar de. Metodologia do trabalho científico: métodos e técnicas da pesquisa e do trabalho acadêmico. 2. ed. Novo Hamburgo: Feevale, 2013. 274p.

RAUSCHMAYER, H., GALDINO, M. A. Os Impactos da Regulamentação ANEEL/482 e da Legislação Tributária no Retorno Financeiro de Sistemas Fotovoltaicos Conectados à Rede. In: CONGRESSO BRASILEIRO DE ENERGIA SOLAR, 5. [Anais...]. Recife. Disponível em: http://www.solarize.com.br/downloads/CBENS impactos regulamentacao.pdf.

SANTOS, Antonio Raimundo dos. Metodologia científica: a construção do conhecimento. 6. ed. rev. Rio de Janeiro: DP \&A, 2004. 166 P.

SANTOS,F.C.M., SANTOS,F.M.S.M. Geração distribuída versus centralizada. Millenium. Journal of Education, Technologies, and Health, v. 13, n. 35, 2016.

SILVA, R. M. Energia solar no Brasil: dos incentivos aos desafios. Brasília: Núcleo de Estudos e Pesquisas/CONLEG/Senado, fev. 2015 (Texto para Discussão no 166). P.815. Disponível em: www.senado.leg.br/estudos. Acesso em: 22 abr. 2018.

TEIXEIRA, A.; CARVALHO, M.; LEITE, L. Análise de viabilidade para a implantação do sistema de energia solar residencial. 20 p. Universidade de Belo Horizonte, Belo Horizonte, 2011.

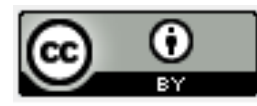

Artigo recebido em: 20/08/2019 e aceito para publicação em: 01/07/2021

DOI: http://dx.doi.org/10.14488/1676-1901.v21i2.3582 